\title{
Numerical simulation of airflow around the evaporator in the closed space
}

\author{
Tomáš Puchor ${ }^{1, *}$, Roman Banovčan ${ }^{1}$, and Richard Lenhard ${ }^{1}$ \\ ${ }^{1}$ University of Žilina, Faculty of Mechanical Engineering, Department of Power Engineering, Univerzitna 1, 01026 Žilina, Slovakia
}

\begin{abstract}
The article deals with a numerical simulation of the forced airflow around a evaporator with the finned tubes in the electrotechnical box, by finite volume method in the program ANSYS Workbench. The work contains an analysis of the impact of forced airflow on the evaporator with the various seated the electrical components. The aim of the work is to find out the most effective way of heat dissipation by forced convection from the electrical components in the closed space with lowest pressure loss.
\end{abstract}

\section{Introduction}

One of the biggest constraints on the electronics industry is the efficient cooling of the system, which ensures continuous production of high heat. Because the heat generated by the devices needs to be efficiently taken off. All electronic components generate heat during their operation. This heat needs to be dissipated to avoid partial or total damage to components and thus avoid making the entire device stopped working. One way to remove heat is to use a thermosiphon loop heat pipe. Cooling systems used in electrical cabinets have been dealt with generated heat by the supply of ambient air at a lower temperature and the extraction of heated air from the inside of the cabinet through the gratings on the cabinet walls. The new solution focuses on separate enclosed air circulation inside the electrical cabinet to prevent contamination of the surface of the electrical components with dust from the surrounding environment. The electrotechnical box with heat exchanger and whole loop thermosyphon can be seen in figure 1 [1]. In this way, maintaining the clean surface of the components and achieving a non-changeable thermal bridge caused by dust is achieved.

The method for removing generated heat inside the electrical cabinet is solved by separated circuit which consists of a heat source and an exchanger. The heat is supplied from source to exchanger by fan. The source of heat transfer mediation between the heat source and the exchanger is air. The air flow between the ribs of the heat exchanger. The space between fins acts like pressure barrier that the air flowing from the fan must overcome. When the air flows through the space, the part of mechanical energy is converted to heat by the influence of viscosity. If we do not consider air compressibility, the loss of mechanical energy will result in a loss of pressure. We are talking about pressure losses [2].

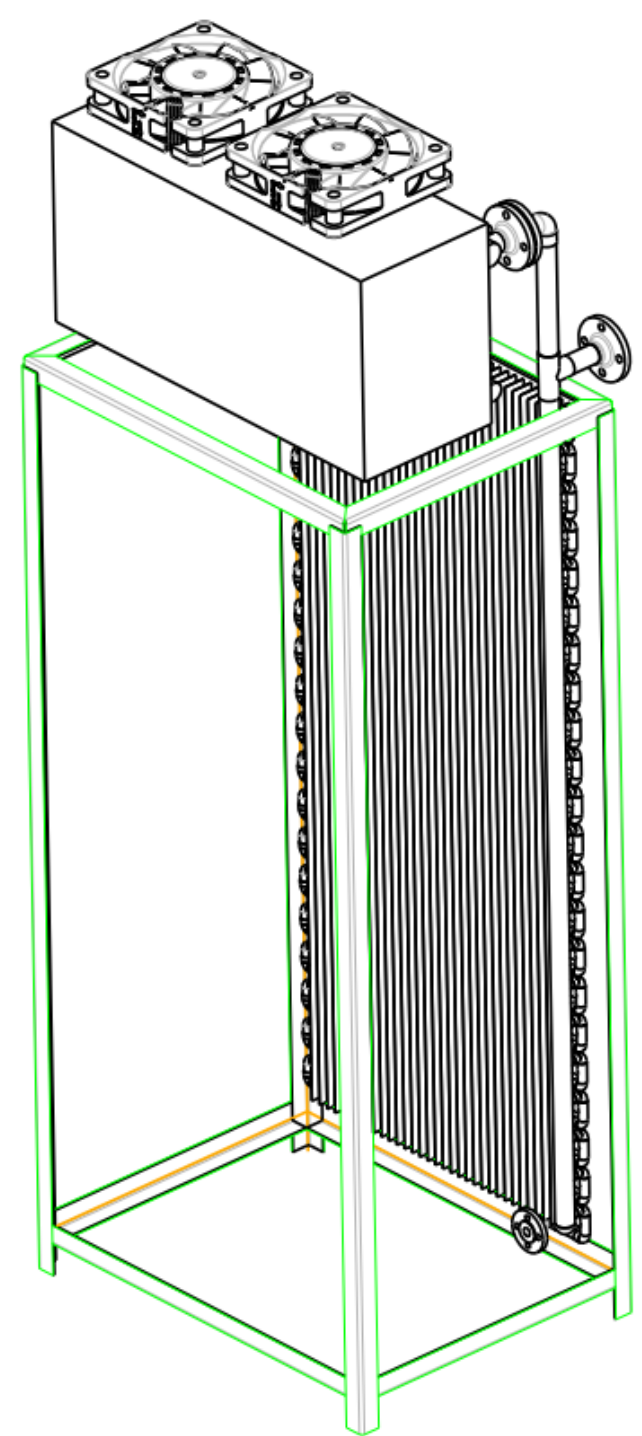

Fig. 1. Electrotechnical box with heat exchanger. 


\section{Heat exchanger}

The heat exchanger consists of vertical fins placed on the horizontal tube of figure 2 . The dimensions of the fins are shown in Table 1 . Tubes with a diameter of $15 \mathrm{~mm}$ are passing through the blades at a distance of $50 \mathrm{~mm}$ from each other. The front and the back wall of the exchanger is closed to form rectangular profile ducts in space between the fins. The space of the exchanger fins is examined for the pressure loss and changes gradually by $0.5 \mathrm{~mm}$ from $1.5 \mathrm{~mm}$ to $3.5 \mathrm{~mm}$. The thickness of the ribbons is $0.25 \mathrm{~mm}$. To simulate the flow, the thickness of the lamellae is negligible [3].

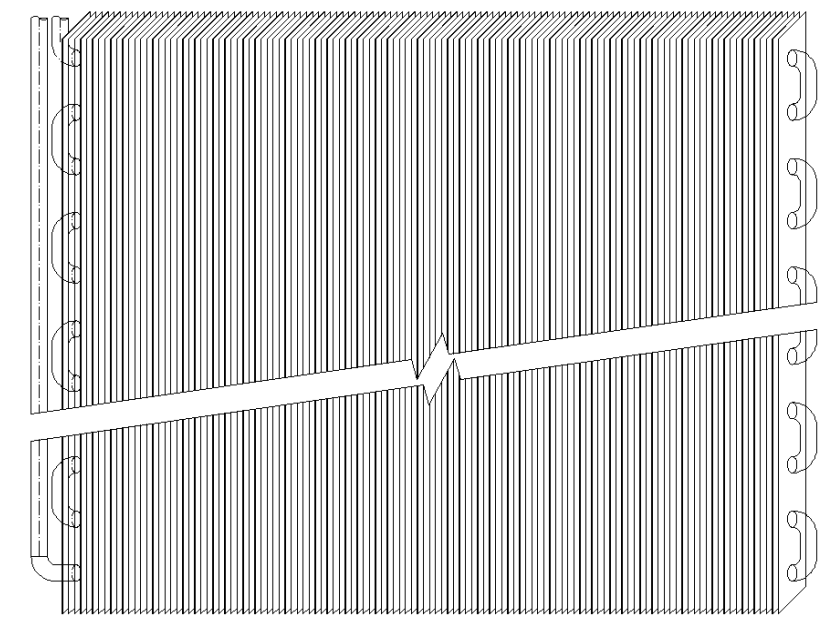

Fig. 2. Heat exchanger (detail).

Table 1. Dimensions of exchanger.

\begin{tabular}{|c|c|}
\hline Fins & \\
\hline Quantity & 240 \\
\hline Diemsnions (mm) & $50 \times 1600$ \\
\hline Thickness (mm) & from 1.5 to 3.5 \\
\hline Distance (mm) & aluminum \\
\hline Material & \\
\hline Pipes & 32 \\
\hline Quantity & 15 \\
\hline Diameter (mm) & 660 \\
\hline Lenght (mm) & cupper \\
\hline Material & \\
\hline
\end{tabular}

\subsection{Simplified model}

Due to the complexity and size of the model, therefore, a simpler model was made to fit only necessary part to perform simulation and to obtain the best results. One space could be used as a model due to the repeated fins spacing. However, the model which consisted of three fins and thus two spaces was chosen. Marginal spaces were modelled with half thickness to match symmetry on both sides of the model. Part of this modified model can be seen in figure 3 .

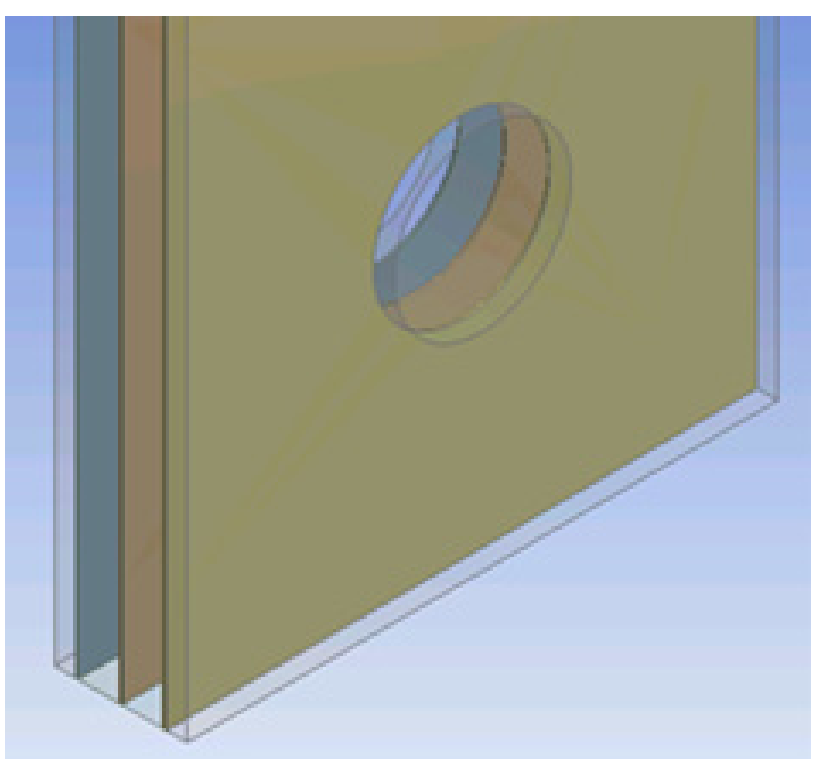

Fig. 3. Model part.

\section{Mesh quality}

To make simulations, it was necessary to design a sufficient model of the part of the exchanger and the mesh network to suit the correctness of the calculation. Model consists from seven bodies in one part. On the first body, the symmetry part was created edge sizing including top and bottom edge and all 32 holes. Edges sizing was chosen as definition for Number of Divisions with total of 80 . The next step was to apply sweep method on this first body with manual source on one face. Number of divisions was chosen with 5 sweep number of divisions. The next sweep method was applied on second body with same settings. Only the sweep number of divisions was setted up to 3 . On the third body, represented as the full air space, the sweep method was with 10 sweep number of divisions. The steps were applied similar for all fins bodies, air spaces and symmetries. Each second body was suppressed because it was considered as not necessary for current simulation. This suppressed bodies matched fins. These hidden bodies will be unsuppressed in another simulation with porous media. The mesh was generated with no problems as seen on figure 4 . In Table 2 . is the number of cells for each rib spacing along with orthogonal quality and orthogonal skewness [4]. 
Table 2. Mesh information's.

\begin{tabular}{|c|c|c|c|c|c|}
\hline & \multicolumn{5}{|c|}{ Space (mm) } \\
\cline { 2 - 6 } & 1.5 & 2 & 2.5 & 3 & 3.5 \\
\hline $\begin{array}{c}\text { Number } \\
\text { of cells }\end{array}$ & 1561370 & 1374330 & 1287960 & 1148260 & 1109990 \\
\hline $\begin{array}{c}\text { Orthogonal } \\
\text { quality }\end{array}$ & 0.12 & 0.16 & 0.19 & 0.23 & 0.21 \\
\hline $\begin{array}{c}\text { Ortho } \\
\text { skewness }\end{array}$ & 0.82 & 0.79 & 0.74 & 0.71 & 0.67 \\
\hline
\end{tabular}

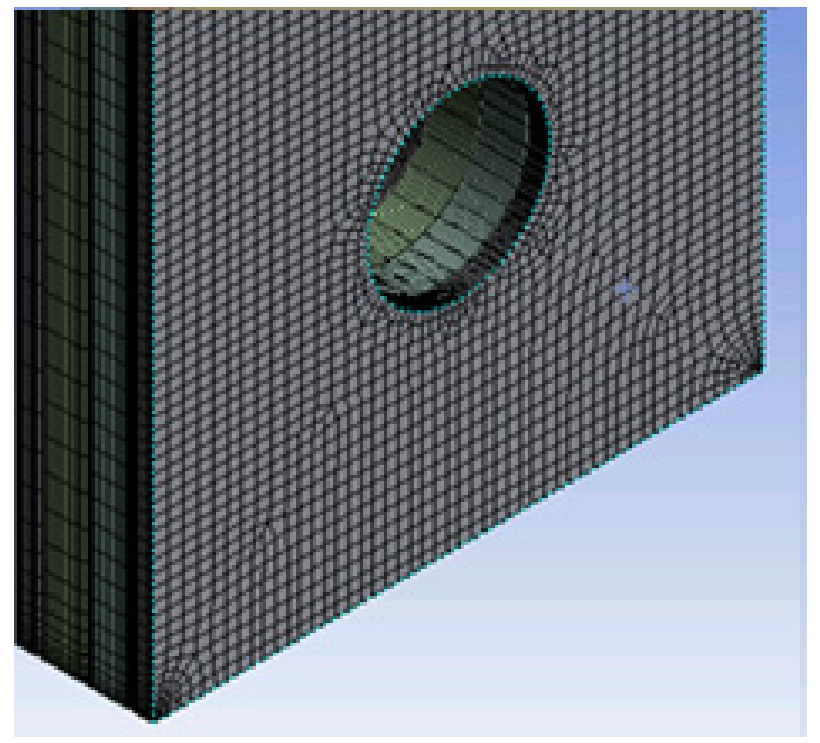

Fig. 4. Meshed model.

\section{Setting up the simulation}

The general simulation setting for each rib spacing was as follows. Energy model and Viscous standard k-e model with enhanced wall function was activated. Medium flowing in the inner-space, was air of a density of $1.225 \mathrm{~kg} . \mathrm{m}^{-3}$ and a viscosity of $1.7894 .10^{-5}$ [5]. In boundary conditions all air inlets were set as a velocityinlet with $2.5 \mathrm{~m} . \mathrm{s}^{-1}$ speed. Turbulence specification method with intensity and hydraulic diameter was chosen with hydraulic diameter for each inlets shown in Table 3. First and last inlet is symmetrical. All outlets was chosen as pressure-outlet. The last step in boundary conditions was to select symmetry on both symmetrical body faces. Solution methods was chosen as coupled and pseudo transient with least squares cell based gradient and momentum as second order upwind. All other spatial discretization was left do default. Solution controls was left to default. Solution initialization was setted up for standard with reference frame as relative to cell zone. Initial values was left do default as well. Solution was initialized. Number of iteration was setted up to 400 and later to more until the simulation was considered as convergent.
Table 3. Hydraulic diameter for distance.

\begin{tabular}{|c|c|c|c|c|c|}
\hline & \multicolumn{5}{|c|}{ Distance (mm) } \\
\cline { 2 - 6 } & 1.5 & 2 & 2.5 & 3 & 3.5 \\
\hline $\begin{array}{c}\text { Hydraulic } \\
\text { diameter } \\
\text { of inlets } \\
\text { (mm) }\end{array}$ & 2.9 & 3.9 & 4.8 & 5.6 & 6.5 \\
\hline
\end{tabular}

The speed $2.5 \mathrm{~m} . \mathrm{s}^{-1}$ was considered based on the chosen fan with characteristic as $\sin$ in figure 5 . The fan was chosen as smallest one as possible based on space inside the electrotechnical box and dimensions of evaporator exchanger. Fan is from company HPM therm s.r.o., from where we also took its characteristics.

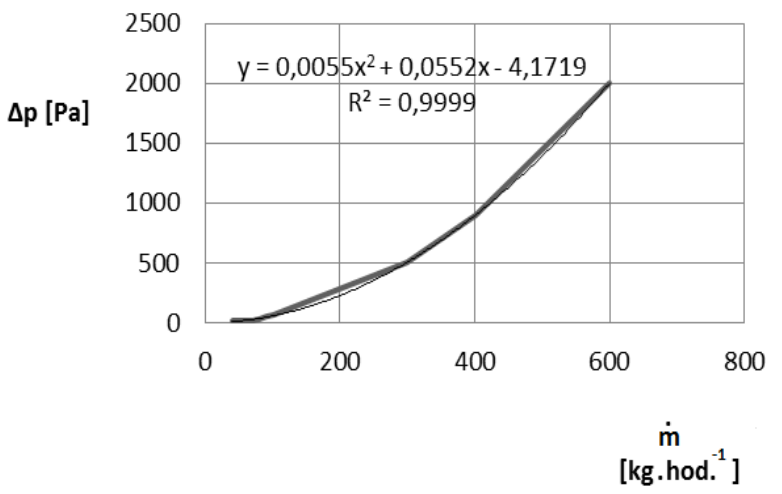

Fig. 5. Characteristics of fan.

\section{Calculations and results}

According to the set parameters, the pressure loss simulations were performed and the results are written in Table 4, and in figure 6 the pressure loss dependence of the rib spacing is seen. From the values we can see that the pressure loss due to rib spacing has an exponential characteristic. The figure 7 shows the pressure loss over the entire length of the gap.

Table 4. Pressure loss.

\begin{tabular}{|c|c|c|c|c|c|}
\hline & \multicolumn{5}{|c|}{ Distance (mm) } \\
\cline { 2 - 6 } & 1.5 & 2 & 2.5 & 3 & 3.5 \\
\hline Pressure (Pa) & 271.7 & 174.9 & 126.8 & 98.82 & 81.4 \\
\hline
\end{tabular}




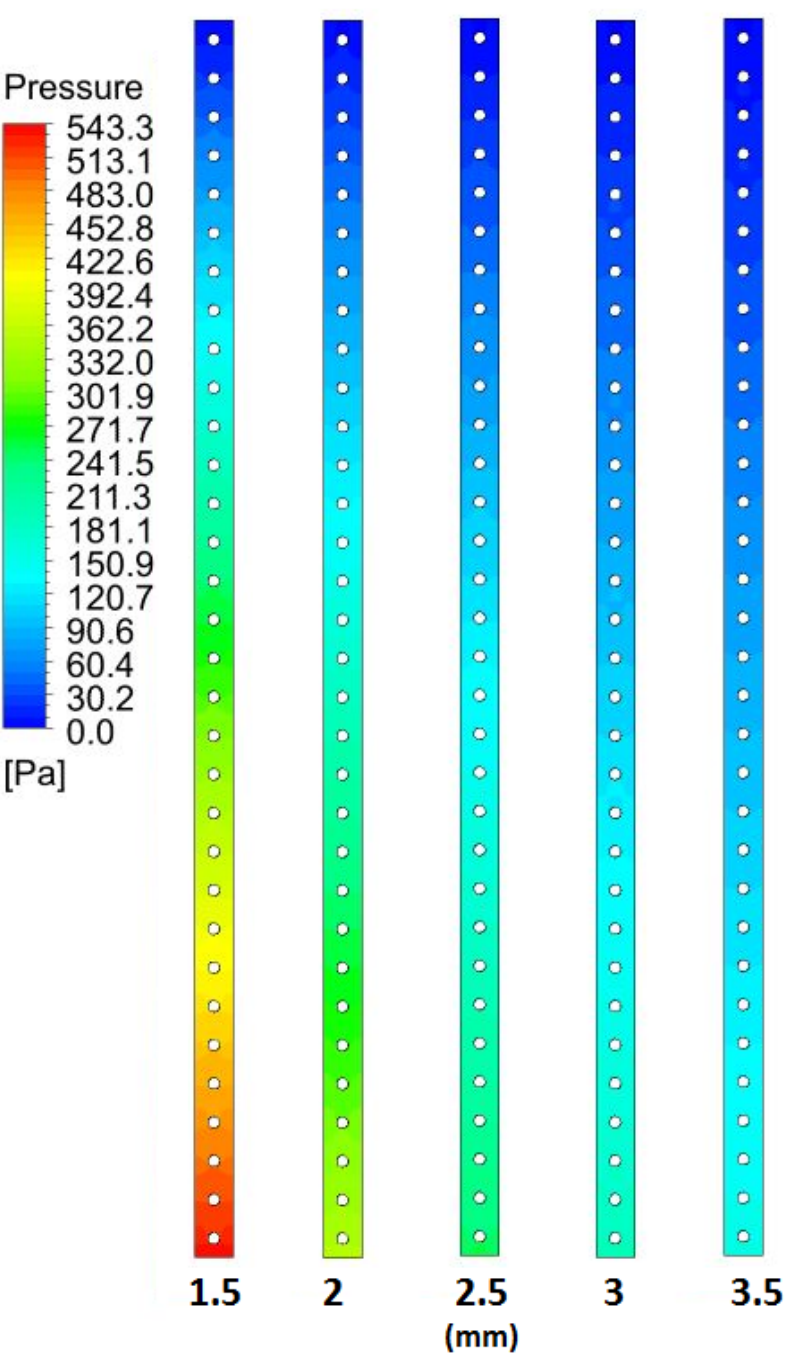

Fig. 6. Pressure loss.

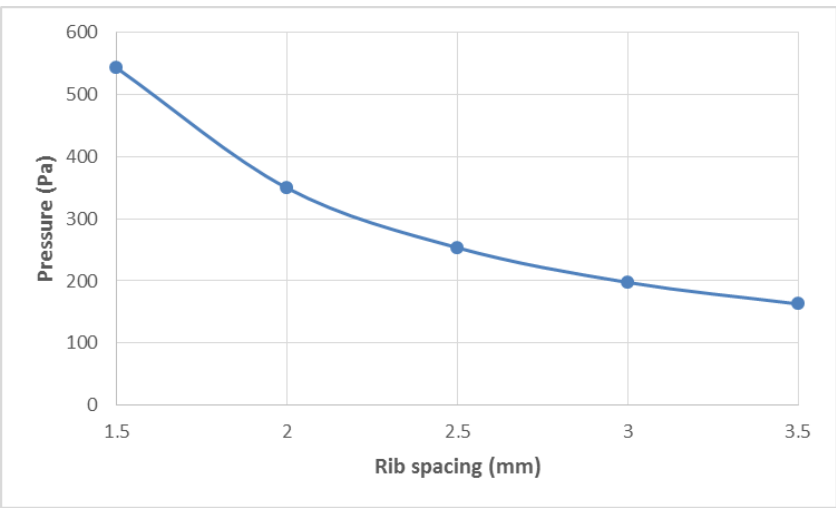

Fig. 7. Pressure loss drop dependance on distance of ribs.

\section{Conclusion}

The aim of the article was to compare the pressure loss in the air flow between the ribs of the loop thermosiphon heat exchanger. By simulations, I found optimal assembly to be a $2.5 \mathrm{~mm}$ gap with a pressure loss of 126.8 $\mathrm{Pa}$. As the ribs approach, the pressure increase sharply, and the rib distance from the $2.5 \mathrm{~mm}$ cause the pressure to decreases gradually negligibly.
These simulations was performed for detecting pressure loss for each space between the fins. The next step will be replacing the ribs with a porous material and therefore it was necessary to determine these pressure drops for comparison with the pressure drops in the porous material. Based on the findings I'll be able to set the correct porosity to achieve the same pressure drops.

This paper was written within the framework of the project APVV-15-0778. Limits of Radiative and Convective Cooling through the Phase Changes of Working Fluid in Loop Thermosiphon.

\section{References}

1. J. Hartenstine, R. Bonner III, J. Motgomery, T. Semenic, Loop thermosyphone design for cooling of large area high flux sources (Proc. Of IPAC, Vancouver, 207)

2. P. Nemec, A. Čaja, M. Malcho, Matematical and computer modelling 57, 126 (2013)

3 . R. Lenhard, M. Malcho, Matematical and computer modelling 57, 112 (2013)

4. D. Reay, P. Kew, R. McGlen, Heat pipes - Theory, design and applications 6 (2014)

5. R. Lenhard, J. Jandačka, AIP Conference Proceedings 1558, 2138 (2013)

6. P. Durčanský, R. Lenhard, J. Jandačka, Acta Polytechnica 55, 4 (2015)

7. M. Brůna, Manufacturing technology 15 (2015)

8. T. Kruczek, Energy 91 (2015)

9. B. Skočilasová, J. Skočilas, AIP Conf. Proc. 1608 (2014)

10. P. Nemec, M. Malcho, K. Kaduchová, EPJ Web of Conferences 143 (2017)

11. J. Kňourek, R. Matas, O. Prokeš, D. Tenkrát, EPJ Web of Conferences (2013). 